Surge of LH occurred during oestrus while $E_{2} 17 \beta$ concentrations were still high. It lasted 13 to 20 hours and was accompanied by an increase in FSH and PRL secretion. While LH and PRL mean levels decreased, FSH concentrations were still increasing. Pulses of LH occurred again about 30 hours after the start of the LH surge.

During the period of oestrus, each exposure to the boar was immediately followed by a peak of PRL which could play a role in the behaviour of the gilt.

\title{
Use of ultrasound echography to study embryonic development in the sow
}

\author{
Martine LEPERCQ ${ }^{(1)}$, Françoise MARTINAT-BOTTE ${ }^{(2)}$, Y. FORGERIT ${ }^{(3)}$, \\ M. TERQUI ${ }^{(1)}$ \\ (1) INRA, Station de Physiologie de la Reproduction, Nouzilly, 37380 Monnaie. \\ (2) I.T.P., 149, rue de Bercy, 75595 Paris Cedex 12. \\ (3) INRA-S.E.I.A., 86480 Rouillé.
}

Ultrasound echography (scanning) allows to visualize embryonic vesicles as early as 18 days after ovulation in the sow. Before, the allantoic and amniotic fluid volumes are too small and undetectable. The purpose of this study was to evaluate with accuracy the conceptus development (embryonic vesicles, embryos) in the first third of pregnancy in order to define the conditions of optimum utilization of this pregnancy diagnosis on the farm.

A total of 233 pregnant sows from 4 herds were scanned 6 times at intervals of 7 days from $21 \pm 2 \mathrm{~d}$ post-insemination. All examinations were carried out by the same operator. The ultrasound scanner used was a TOSHIBA SAL $32 \mathrm{~B}$. For each sow, images of the first three scannings were recorded with a video tape recorder. For each scanning, images were drawn after frame-freeze. This allowed measurement of the size of individual structures within an image : vertical diameter of surface $(n=6622)$ of vesicles, length $(n=253)$ or diameter $(n=585)$ of embryos.

A very rapid growth of vesicles was observed between 20 and $30 \mathrm{~d}$. Their size (diameter of surface) was less variable. After $30 \mathrm{~d}$ growth was slower.

Embryos were visible from $21 \mathrm{~d}$ post-insemination. Between 21 and $37 \mathrm{~d}(\mathrm{r}=0.97)$ their growth was linear. Nevertheless between 21 and $30 \mathrm{~d}$, images were easy to interprete due to the small size of embryos relative to the volume of fluid. It is therefore recommended to perform pregnancy diagnosis during this period. Prediction of the litter size by enumeration of vesicles at 3 , 4 or 5 weeks is not possible, the calculated coefficients of correlation being too small ( $\mathrm{r}$ : ranging between 0.16 and 0.27 ).

\section{Pregnancy diagnosis by ultrasound echography : an aid to control pig reproduction}

\author{
F. MARTINAT-BOTTE ${ }^{(1)}$, F. BARITEAU $^{(2)}$, O. TEFFENE ${ }^{(1)}$, M. TERQUI $^{(3)}$ \\ (1) I.T.P., 149, rue de Brecy, 75595 Paris Cedex 12. \\ (2) INRA-S.E.I.A., 86480 Rouillé.
}

(3) INRA, Station de Physiologie de la Reproduction, Nouzilly, 37380 Monnaie.

In the sow, we have previously shown that ultrasound echography (scanning) can be an aid to the early diagnosis of pregnancy. This technique has been used since 1984 in about fifty herds. 